\title{
The new industrial revolution should take people as the foremost
}

\author{
Wenjuan ZHANG, Lun XIAO, Ying YU, Ye CHAO
}

Sino-German College of Applied Science, Tongji University, Shanghai, 200092

zhangwenjuan@tongji.edu.cn, xiaolun1023@tongji.edu.cn,

cdhawyy@tongji.edu.cn, jarrrice@163.com

Key word: the new industrial revolution, social innovation, human-oriented

Abstract: The new industrial revolution which initiated by digital technology, internet and new energy innovation has coming and will bring profound changes to industry, economy and society all over the world, it's a long-term, inclusive and sustainable industrialization process. Based on the analysis of main features of the industrial revolution, this paper points out that the purpose of this revolution is to promote a more sustainable and comprehensive development of human being and the society. So the revolution should be looked as a complicated sociotechnical system. And a people-oriented principle should be established when make any decision or choice, and social innovation solution and technical innovation solution must be applied coordinately and systematicly. When the two solutions conflict with each other, changes in the technical system should be made to adapt to the social system.

\section{Introduction}

In 1987, World Commission on Environment and Development put forward the concept of sustainable development in its report "Our Common Future". After nearly 30 years' development and evolution, sustainable development has formed three pillars which comprise economic development, social progress and environmental protection. In September 2015, the United Nations Development Summit summarized core related elements as 17 interrelated goals of sustainable development in the form of consensus document "Change Our World - Sustainable Development Agenda In 2030". The ninth goal is "to promote inclusive and sustainable industrial development" ${ }^{\text {,1] }}$.

\section{Main content and characteristics of the new industrial revolution}

The new industrial revolution which featured digital technology, internet and new energy has gradually expanded around the world. Looking back on history, the past industrial revolutions all triggered by technical revolution firstly, then developed along the chain of "Science - Technology Production - Industry - Economy - Society". Whether the science and the new technologies can significantly change the social production style and human lifestyle is one important criteria which is used to judge it was a revolution or not. This time of industrial innovation also triggered by some new innovative technologies, such as new energy and new communication technology, the core of which is the intelligent micro-fabrication technology. The new industry revolution marked by the use and deep cycling production of artificial chemicals production; and the social system revolution marked by globalization; the last stage is to form a new unity of human and nature. 
The new industrial revolution emphasizes sustainability, integrity, innovation and globalization. The core field of this revolution is the whole industry. In this process the industrial products and services will be fully cross-penetrated, The proportion of services attached to the product continues to increase ${ }^{[2]}$. The design and manufacturing process of products convert to a digital, flexible and decentralized mode from large-scale standardization style, and many steps of that can be established and finished online and on the cloud computing platform. The requirements for complex, special and personalized products are increasing rapidly. The design-driven innovations are getting unprecedented attention. More and more technical breakthroughs are achieved through the integration of different technologies. Integration and synergy play key role in this process. The existing pattern of industry division and structure are changing, but interpersonal communication will never be subjected to the national boundary, region and time constraints. And the future human lifestyle becomes more flat.

\section{The revolution will change human's working relationship and social life}

The coming decades are the very important re-developing periods for industrial sector especially for manufacturing industry. The human development index will continue to improve. We can get a lower poverty rate, lower consumer prices and can find many highly profitable investment opportunities new technologies may expand and increase technology-intensive industries, and offer new opportunities for the unemployed workers because of the use of CNC machine ${ }^{[3]}$. Evidently, the work performed by the labor on the shop floor in a factory of the future will differ significantly from the situation in today's factory ${ }^{[4]}$. So does human being's personal life and the whole society.

\section{Needs for new production relationship}

In the future, working will be more flexible in time and workspace, workflow will be more digitized, changeable, decentralized and transparent.the working environment will be more open and creative. So the employees (especially those highly skilled labors) can balance their work and life easier than before. Similar to previous industrial revolutions which invented the factory system and the modern corporate system, this new revolution will also result in the emerge of a new kind of production relationship among labor, material and machine. For example during the 1980s, we faced the selection dilemma of "human or machine". Nowadays, we are no longer concerned about this selection, we need only to think how to establish a good cooperation relationship and can exchange information autonomously between "man and machine".

\section{Shift from factory production to social production}

With the continuously mature and cost-lower of some new technologies, such as 3D printing technology, small companies even an individual can independently complete the whole manufacturing process which only can be done on a complete production line in the past. Therefore, in addition to the manufacturing of some necessary parts and products, the processes of most manufacturing on the shop floor in a future's factory can be subdivided indefinitely and the goods can be produced in the way of "social production". Thus reduces the total cost of "from innovation into manufacturing".

Because production mode will become more flexible and diversified, workers should collaborate and communicate with each other cross-borderly. In the future, people, objects, processes, services, 
and data will be connected by internet. The physical world and the virtual world will be integrated together and a dynamic, real-time optimized, self-organized value-creating networks will be formed, where collaboration is a prerequisity in order to achieve an effective system. In 28 January 2016, the researchers from Google Inc. published a cover paper in the journal of Nature which claimed that their artificial intelligence (AI) machine had beaten a human champion of the game of GO. This phenomenon is regarded as "a historic milestone of artificial intelligence". In fact as early as 2005, there was another very interesting CHESS game carried out among two amateur players equipped with ordinary-performance computer, a chess master, and a high-performance AI machine. The winner was that two ordinary players. This surprised result reminded us that the correct and deep cooperation between human and computer, between human and human can empower people with higher ability which an individual can not have, so people can control complex situation and make right decision quickly, finally get the best results.

\section{Change of labor intensity and employment structure}

Technological revolution will promote labor-intensive economy to capital-intensive and technology-intensive economy transition. If the main transition focuses on labor-saving, there will be an increase of capital-intensive industries and the number of employees and the structure of employment will change accordingly. If the main transition is skill-based, there will be an increase of the demand for skilled labors and the reduction of unskilled labors. During this transition some types of job especially in the fields of secondary skills and middle-income will disappear because of the realization of automation and digitalization of the factory. Thus will leads to the increase of unemployment rate. The career fields which require more experience and interaction rather than mechanical operation become increasingly important. And this innovative will also affect income distribution of the labor through the way of skill premium. The phenomenon of wage inequality between skilled workers and unskilled workers will become serious.

\section{Labors have to improve new skills and qualifications}

Looking back on the development of human history, every previous industrial revolution liberated human labor and were replaced by certain new advanced machines. That is true for this industrial revolution. Not only manual labor but also part of mental work (for instance, human's logical analysis ability and calculating ability) will be replaced by the machine or robotics and the extent is greater than before. In the manufacturing network of this time which charactered by cyber-physical system(CPS), people will act as developer, designer and co-producer, so they will get used to utilize more complex and autonomous equipment. In the era of traditional large-scale standardized production line, workers are positioned basing on the function of the whole production line, does not advocate individuality and creativity; but in an intelligent factory of the future, the workers will be liberated from simple repetitive activity and their creation instincts will be released. The widely use of internet of things, cloud computing, big data, 3D printing and other technologies strengthen the networked cooperation, make innovation more convenient and feasible. The add-value that results from innovation will receive more attention. Workers will be more involved in the decision-making and management activities. A high degree of personal responsibility and autonomy will be combined with decentralized leadership and management methods. 


\section{The new industrial revolution is a sociotechnical system}

\section{Technical innovation - should serve the social objectives}

The new industrial revolution is a profound change which is triggered by technology, will ultimately change our entire human society, lead us enter into an era of knowledge and creativity, the construction and advancement of social cultural environment is the necessary precondition.In this sustainable and comprehensive process, human being will become the most important manufacturing factor beyond land and capital, and play a more essential role in the industrial production. "Take people as the foremost" is the core principle of this revolution.

E.L.Trist, the founder of sociotechnical system, and his colleagues in the UK Tavistock Institute insist on: in a sociotechnical system, manager's main task is to ensure the coordination of social system and technical system. Technical system is the intermediary between organization and its environment. But when the conflict happens technical system usually should make some changes to adapt to the social system ${ }^{[5]}$. In the future innovation must implement the technical innovation and the social innovation at the same time. Further more, the two must coordinate and cooperate with each other. For this purpose, people and technology system are bound to establish a good interaction and cooperation to achieve the best combination.

\section{Social innovation -effective means to social challenges}

This new industrial revolution is a long-term, inclusive and sustainable industrialization process. It will directly affect the education and talent cultivation, organization structure, management pattern and will also change the social governance paradigm. The new industrial revolution can not only promote the development of human civilization and social progress, but also bring new serious risks and challenges to the whole society. For instance, some industrial types of work will disappear, work environment and tasks become more complex and flexible, employees have to enhance their professional competence and so on. Social innovative methods can offer new solutions and deal with such social challenges. Rather than efficiency and effectiveness, social innovation pay more attention to sustainability and fairness. These kinds of innovation try to bring great social benefits to the public rather than a single enterprise or an individual. And the public is also deeply involved in the process of program designing and decision-make. Its form of expression can be the provisions of laws and regulations, new organizational structures, new business models, new products, new processes and so on ${ }^{[6]}$.

But only through technological innovation, social innovation can diffuse faster and play a greater role. And only with the cooperation of social innovation and technological innovation at the same time, can the achievement of a long-term economic growth and the development of a harmonious society be enjoyed by more people.

\section{Conclusion}

Technical innovation, regarded as one of the main drivers of long-term economic growth. However, can realize socially inclusive and environmentally sustainable industrial development simultaneously only under the complex system interventions and scientific management. Therefore, in response to the new industrial revolution, we must always strengthen by a human-centered manner and use 
technical innovation and social innovation simultaneously to ensure the public rather than just a few classes or groups to benefit from this historic opportunity, to promote the sustainable economic development, to provide equal opportunity for the society, to realize the fair distribution of interests and sustainable environment and eventually to improve the quality of our total human beings' lives.

\section{References}

[1] Wang. Global sustainable development into the 2.0 era (the trend). People's Daily [N]. 2015 Nian 09 Yue 13 Ri http://news.ifeng.com/a/20150913/44641521_0.shtml

[2] Ulrich Sendler editor, Deng Min, Lee Min now translated Industry 4.0: the impending onslaught of fourth industrial revolution [M] Machine Press 2015.

[3] UNIDO Industrial Development Report 2016: The role of technology and innovation for inclusive and sustainable industrial development [M] .2015 [4] VDI、ASME. Industry 4.0 A discussion of qualifications and skills in the factory of the future [M].2015

[5] Wikipedia.the free encyclopedia.Sociotechnical system. https://en.wikipedia.org/wiki/Sociotechnical_system

[6] Ebert Foundation of Germany. Industrial Society Innovation Policy 4.0 [M] .2015 